\title{
Rheological behavior of $\beta$-Ti and NiTi powders produced by atomization for SLM production of open porous orthopedic implants
}

\author{
G. Yablokova ${ }^{\text {a,* }}$, M. Speirs ${ }^{\text {b }}$, J. Van Humbeeck ${ }^{\text {a }}$, J.-P. Kruth ${ }^{\text {b }}$, J. Schrooten ${ }^{\text {a }}$, R. Cloots ${ }^{\text {c }}$, F. Boschini ${ }^{\text {c }}$, \\ G. Lumay ${ }^{\mathrm{c}}$, J. Luyten ${ }^{\mathrm{a}}$ \\ a KU Leuven, Department of Materials Engineering, Kasteelpark Arenberg 44 bus 2450, Leuven (Heverlee) 3001, Belgium \\ ${ }^{\mathrm{b}}$ KU Leuven, Department of Mechanical Engineering, Division Production Engineering, Machine Design and Automation, Celestijnenlaan 300A bus 2420, Leuven (Heverlee) 3001, Belgium \\ ' University of Liege, Advanced Powder Technologies and Innovative Solutions, Allée de 6 août, 17 Bât, B5a, Liège 4000, Belgium
}

\section{A R T I C L E I N F O}

\section{Article history:}

Received 14 January 2015

Received in revised form 4 May 2015

Accepted 9 May 2015

Available online 15 May 2015

\section{Keywords:}

Rheological behavior

B-Ti powders

Flowability

Plasma atomization

Gas atomization

Selective Laser Melting

\begin{abstract}
A B S T R A C T
The growing interest for Selective Laser Melting (SLM) in orthopedic implant manufacturing is accompanied by the introduction of novel Ti alloys, in particular $\beta$-Ti for their excellent corrosion resistance as well as favorable combination of high mechanical strength, fatigue resistance and relatively low elastic modulus. As part of the SLM process for producing quality $\beta$-Ti parts powder flowability is essential to achieve uniform thickness of powder layers. In this work the flowability of different gas atomized $\beta$-Ti, including NiTi, powders has been studied. Their rheological properties were compared to those of commercially available plasma-atomized Ti-6Al-4V powder using a newly developed semi-automatic experimental set-up. Not only the particle size, shape and size distribution of the powders display a large influence on the powder flowability but also particle surface properties such as roughness, chemical composition and the presence of liquid on the surface of the particles. It was found that plasma or gas atomization production techniques for SLM powder have a considerable effect on the particle topography. Among the powders studied regarding SLM applicability only rheological properties of the fine size fraction $(25-45 \mu \mathrm{m})$ of Ti-45Nb didn't conform to SLM processing requirements. To improve flowability of the Ti-45Nb powder it was annealed both in air and argon atmosphere at $600^{\circ} \mathrm{C}$ during $1 \mathrm{~h}$, resulting in an improved rheological behavior suitable for SLM processing.
\end{abstract}

(c) 2015 Elsevier B.V. All rights reserved.

\section{Introduction}

Despite decades of scientific research and new surgical approaches used in orthopedics, implant loosening still remains the most frequent cause for revision surgery. The most widespread reasons of implant loosening are stress-shielding effect, infection, wear debris-induced osteolysis and inadequate fixation to the bone [1,2]. Current state-ofthe-art materials and techniques are keen to overcome the abovementioned drawbacks of orthopedic implants. For example, the use of open-porous materials capable of stimulating bone cell ingrowth approved the quality of implant fixation to bone. In addition, porosity and pore geometry variations can allow for stiffness-compatible implants to better match patient-specific requirements [3,4].

Open-porous implants have been produced with current biomedical alloys such as $\mathrm{Ti}, \mathrm{Ti}-6 \mathrm{Al}-4 \mathrm{~V}$ and $\mathrm{Ti}-6 \mathrm{Al}-7 \mathrm{Nb}$ powders [5-8]. However, these materials suffer from a mismatch in the Young's modulus between bone and implant material as well as insufficient

\footnotetext{
* Corresponding author: Tel.: + 3216321263 .

E-mail address: ganna.yablokova@mtm.kuleuven.be (G. Yablokova).
}

biocompatibility $[9,10]$. The use of novel $\beta$-Ti alloys is expected to reduce stress-shielding phenomena due to their lower Young's modulus. Moreover, these alloys can be produced without toxic alloying additions [11].

Selective Laser Melting (SLM) is an emerging production method to fabricate (customized) complex Ti alloy implants. It has the potential to allow customization and optimization for each case and patient. It is a manufacturing technique in which complex 3D parts can be built up directly from a CAD model by selective melting of successive powder layers using a focused laser beam (Fig. 1) [5,12]. The first step in the SLM process is to dispense a thin powder layer on the build platform. Powder is brought from a feed container to the build platform by a polymer coater (Fig. 1). To get a homogeneous and dense powder layer powder should have good flow characteristics. Each powder aimed for SLM applications must satisfy this requirement and if not met should undergo study on the improvement of its flow behavior. Similar studies have already been carried out for Ti-6Al-7Nb powder by $\mathrm{T}$. Marcu et al. resulting in the delivery of powder with very good flow properties [13].

Rheology is the study of the flow of complex fluids (suspensions, pastes, creams, granular materials, etc.) under applied forces. Granular 

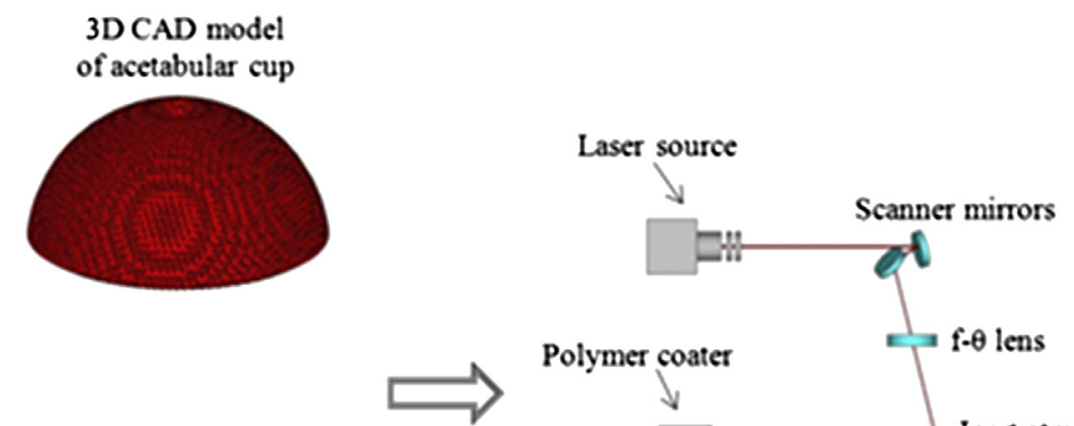

\section{SLM produced acetabular cup}

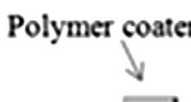

Powder
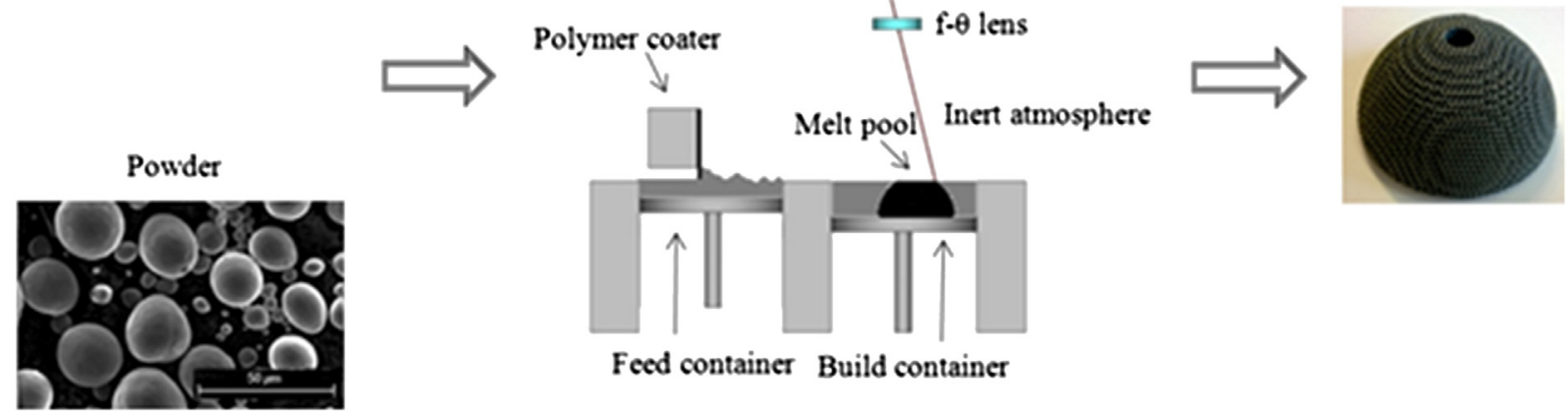

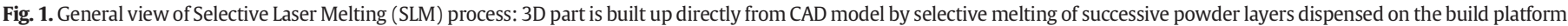
using a focused laser beam.

materials have to be regarded as a particular case due to their ability to behave like a solid (static state) or like a fluid (dynamic state) according to the applied stress. Moreover, granular material rheology is influenced by a large set of parameters: grain shape and size, grain surface roughness, grain chemical properties, inter-grain cohesive forces, etc. Therefore, the measurement of granular material rheological properties is a complex task. The cohesive forces are induced by van der Waals interactions, capillary bridges and electrostatic charges. Typically, when the grain size is inferior to $50 \mu \mathrm{m}$, the cohesive forces acting on one grain are higher than the grain weight. Therefore the macroscopic properties of the grain assembly are mainly determined by these cohesive forces. A quantification of these cohesive forces is essential to optimize processes involving granular materials.

This work studies the flowability for SLM processing of three different gas atomized $\beta$-type Ti powders, namely non-toxic Ti-45Nb, Ti-23Nb-10Zr and also NiTi powders, the latter as a benchmark $\beta$-type Ti with already several medical applications based on its superelasticity and shape memory effect [14], but not yet through SLM based processing.

To assess powder flowability, the Hall-flowmeter has been widely used as a standard method. Unfortunately, the results obtained with this measurement method are limited and the interpretations are difficult [15]. During the last decade interesting techniques such as improved tapped density measurement [16], rotating drum method [17], shear cells [18] and powder rheometers [19] have been developed. However, the evolution of this field is still in its infancy. Even from a fundamental point of view, the determination of the physical laws that govern the behavior of a granular material is still a matter of intense debates in the physics community. In the present work gas atomized $\beta$-Ti alloy powder rheology was investigated by using a new set of characterization techniques. The powder characteristics are measured through (i) an original heap shape analysis method, (ii) a rotating drum flowability measurement method, and (iii) an improved tapped density method. The association of these static, semi-static and dynamic information allows the determination of the powder complex rheological properties. Both heap shape and rotating drum methods are particularly appropriate for the analysis of powders involved in SLM applications. In addition the chemical composition of the $\beta$-Ti powders was measured to interpret the flowability results [17]. Finally the rheological behavior of all powders was compared to that of commercial plasma atomized Ti-6Al-4V powder specially produced for SLM applications.

\section{Materials \& methods}

\subsection{Powder synthesis}

NiTi bars (Department of Materials Engineering, KU Leuven, Leuven (Heverlee), Belgium), Ti-45Nb ingots (ATI Wah Chang, Huntsville, USA) and Ti-18Nb-11Zr ingots (Xi'an Satei Metal Materials Dev. Co. Ltd., Xi'an, China) were processed into powder by gas (argon) atomization (TLS Technik GmbH \& Co., Bitterfeld, Germany) and afterwards sieved into different fractions. Two fractions with a particle size ranging respectively from 25 to $45 \mu \mathrm{m}$ and from 45 to $100 \mu \mathrm{m}$ were selected for further SLM processing. Due to processing difficulties during atomization the composition of the Ti-18Nb-11Zr ingot was changed, most likely by a contamination of residues of previously atomized Ti-45Nb material. To homogenize this contaminated powder it was mixed with a rotation speed of $70 \mathrm{rpm}$ in a Turbula T2A blender (Willy A. Bachofen AG Maschinenfabrik, Basel, Switzerland) at room temperature, resulting in a final composition of Ti-23Nb-10Zr. Hence the initial Ti-18Nb-11Zr ingot will be further referred to as Ti-23Nb-10Zr powder. The specific approach of the TLS Technik gas atomization was the combination of gas atomization with a crucible free melting process. The induction coil causes melting of a rotating electrode in a non-contact mode. Molten metal flowed down to the cone of the electrode and then led directly through the gas nozzle system, where the metal was atomized. The solidified particles were captured in a powder container [20]. The plasma atomized commercially available Ti-6Al-4V powder (Raymor n.v., Canada) has been taken as a reference material in this work, being an industrial standard for SLM TiAIV powder. Plasma atomization is a patented process developed by Raymor Industries of Canada. In this process, multiple plasma jets converge on a high-purity metallic wire that is fed continuously into a reactor filled with inert gas. Due to the use of hot atomizing argon gas instead of a cold one, as applied in gas atomization, the plasma atomization results in slower cooling rates allowing complete spheroidization of the powder particles [21]. Table 1 summarizes all the studied materials, their corresponding powder densities, powder fractions and weight per powder batch.

\subsection{Thermal treatment of TiNb-1 powder}

Heat treatment of TiNb-1 sample was carried out in a Carbolite general purpose box furnace in air at $600^{\circ} \mathrm{C}$ for $1 \mathrm{~h}$ according to the procedure of 
Table 1

Materials, corresponding powder densities and powder fractions subjected to testing by semiautomatic equipment for the evaluation of rheological properties.

\begin{tabular}{llcll}
\hline Alloy & $\begin{array}{l}\text { Powder } \\
\text { fraction }(\mu \mathrm{m})\end{array}$ & $\begin{array}{l}\text { Powder batch } \\
\text { weight }(\mathrm{kg})\end{array}$ & $\begin{array}{l}\text { Powder density } \\
\left(\mathrm{g} / \mathrm{cm}^{3}\right)\end{array}$ & $\begin{array}{l}\text { Sample } \\
\text { name }\end{array}$ \\
\hline Ti-45Nb & $25-45$ & 0.84 & $5.89 \pm 0.0228$ & TiNb-1 \\
Ti-45Nb & $45-100$ & 2.69 & $5.84 \pm 0.0149$ & TiNb-2 \\
Ti-23Nb-10Zr & $25-45$ & 1.84 & $5.20 \pm 0.0030$ & TNZ-1 \\
Ti-23Nb-10Zr & $45-100$ & 2.78 & $5.24 \pm 0.0217$ & TNZ-2 \\
NiTi & $25-45$ & 1.28 & $6.43 \pm 0.0097$ & NiTi-1 \\
NiTi & $45-100$ & 1.61 & $6.47 \pm 0.0120$ & NiTi-2 \\
Ti-6Al-4V (reference) & $<45$ & 100 & $4.44 \pm 0.0142$ & Ref-Ti \\
\hline
\end{tabular}

Marcu et al. [13]. TiNb-1 powder was also exposed to the same heat treatment in a Carbolite horizontal tube furnace with a protective argon atmosphere to avoid diffusion of interstitial atoms such as $\mathrm{O}$ and $\mathrm{N}$.

\subsection{Powder characterization}

\subsubsection{Particle size, density, morphology and composition}

Particle size distribution was measured by a laser diffraction particle size analyzer Mastersizer (Malvern Instruments Ltd., Malvern, UK) in a dispersed state in liquid ("wet" Laser Diffraction Spectrometry, LDS-W method); number of measurements, $\mathrm{n}=1$. The residual error and variation reported by Malvern are less than 1\% [22]. Powder density was analyzed by Multipycnometer with $\mathrm{N}_{2}$ gas (Quantachrome Instruments, USA); number of measurements, $n=3$. Chemical surface composition, shape and surface topography of the powders were evaluated using the scanning electron microscope (SEM) Philips XL30 FEG equipped with an energy dispersive X-ray (EDX) detector with an ultra-thin window. The surface topography of the different powders was compared qualitatively by the naked eye observation of the SEM pictures. The bulk chemical composition was analyzed using the Varian 720 ES axial simultaneous Inductively Coupled Plasma Optical Emission Spectrometer (ICP-OES) (Varian Inc., USA). Automated qualitative and quantitative analyses were performed using the ICP-OES Expert version 1.2 software (Varian Inc., USA). The signal stability reported by Varian is high with the variation less than $1 \%$ over $8 \mathrm{~h}$ without internal standardization or any form of drift correction [23]; number of measurements $n=3$.

\subsubsection{Powder rheology}

To evaluate the rheological properties of the powders, three recently developed experimental methods (Fig. 2) were used [17]: (i) heap shape method (GranuHeap ${ }^{\circledR}$ instrument) to measure static properties (angle of repose $\alpha_{\mathrm{r}}$, cohesive index $\sigma_{\mathrm{r}}$ and heap height $\mathrm{h}_{\mathrm{r}}$ ), (ii) rotating drum method (GranuDrum ${ }^{\circledR}$ instrument) to measure the dynamic properties (flowing angle $\alpha_{\mathrm{f}}$ and dynamic cohesive index $\sigma_{\mathrm{f}}$ ) and (iii) tapped density method (GranuPaQ ${ }^{\circledR}$ instrument) to measure semi-dynamic properties (Hausner ratio $\mathrm{H}_{\mathrm{r}}$, bulk density $\eta_{0}$ and tapped density $\eta_{500}$ ) $[17,20]$. From the three available $\beta-T i$ and Ti-6Al-4V benchmark powder batches (total weight per batch is shown in Table 1) a random sample of $55 \mathrm{ml}$ was taken to perform heap shape and rotating drum measurements. Tapped density measurements were performed with $25 \mathrm{ml}$ of random powder sample.

2.3.2.1. Heap shape method. A powder heap is created on a cylindrical support to be analyzed by image treatment (see Fig. 2). In order to obtain reproducible results, an initialization tube with an internal diameter equal to the circular support is installed on the support. After filling the initialization tube by hand with a fixed volume of powder, the tube goes up at the constant speed of $5 \mathrm{~mm} / \mathrm{s}$. Thereby, the powder is flowing from the tube to form a heap on the cylindrical support. A controlled rotation of the support allows obtaining different heap projections. In this study, 16 images separated by a rotation of $11.25^{\circ}$ were recorded. A custom image recognition algorithm was applied to determine the position of the powder/air interface. The repose angle $\alpha_{r}$ refers to the angle of
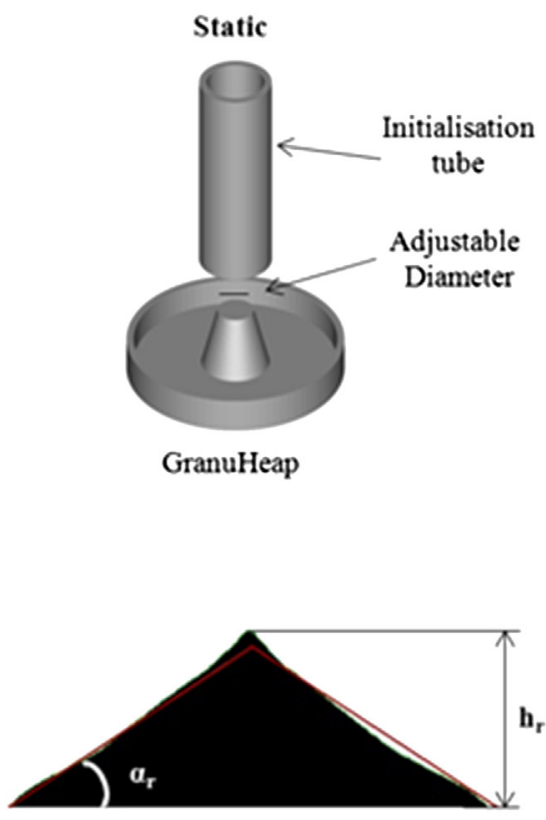

Heap shape

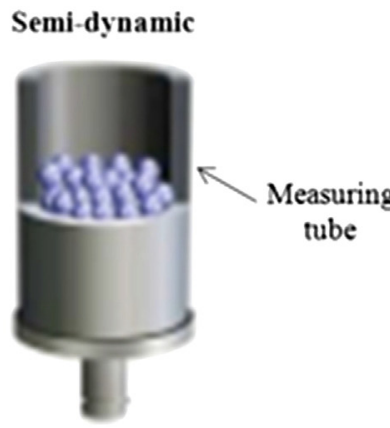

GranuPaQ

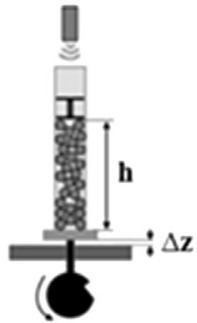

Sketch of the GranuPaQ set-up

A

B

Dynamic

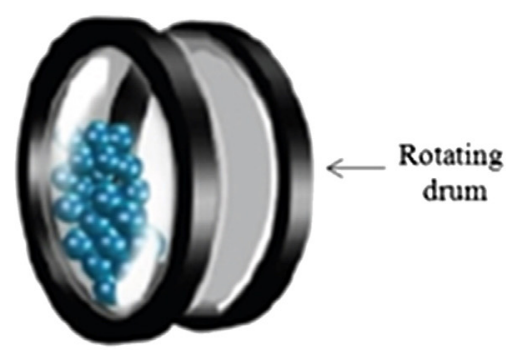

GranuDrum

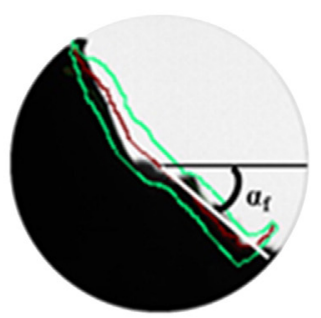

Sketch of the GranuDrum measurement

C

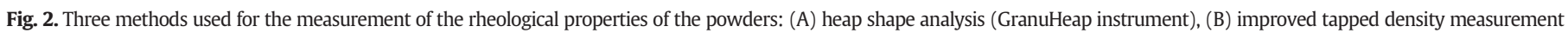
method (GranuPaQ instrument), and (C) flow analysis in a rotating drum (GranuDrum instrument) [16] 


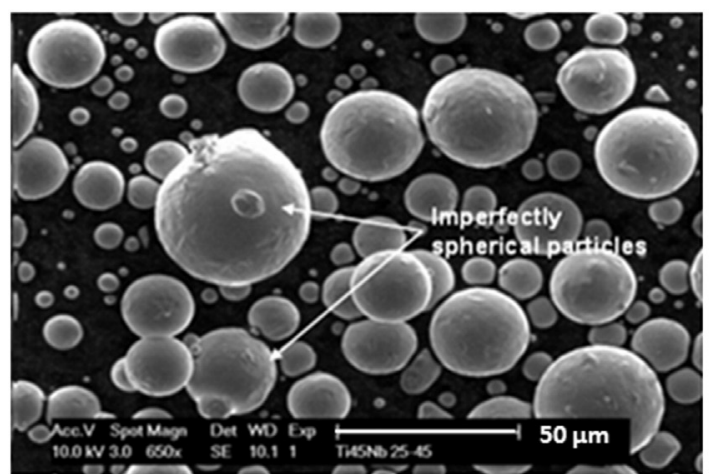

A

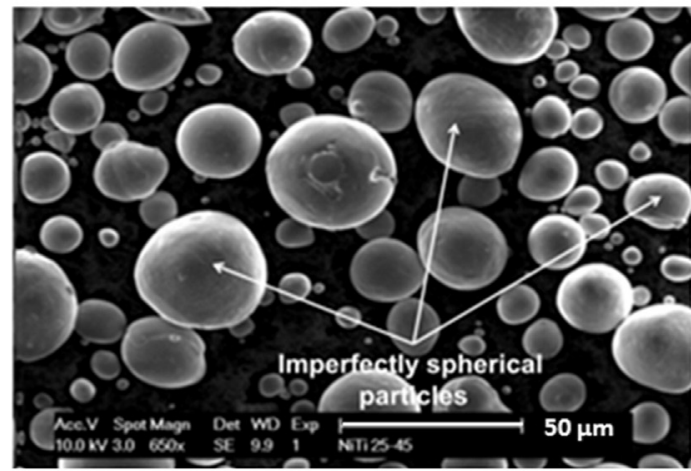

$\mathrm{C}$

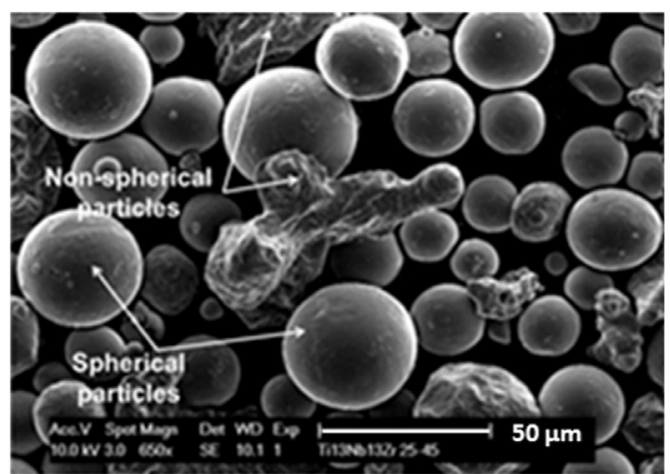

B

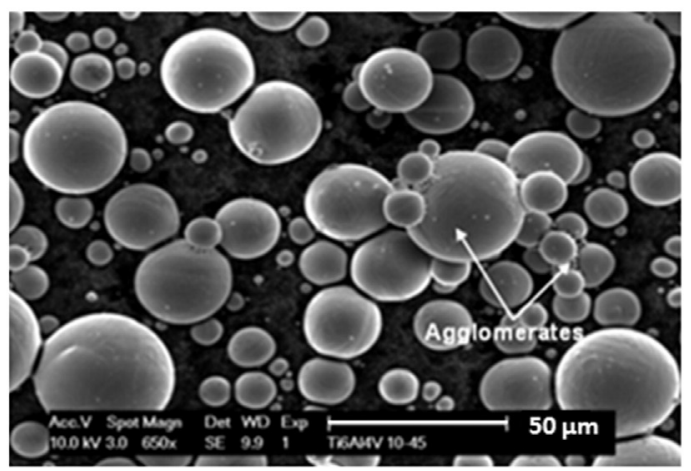

D

Fig. 3. SEM pictures and the corresponding EDX measurements of 25-45 $\mu \mathrm{m}$ fraction powders: (A) TiNb-1, (B) TNZ-1, (C) NiTi-1 and (D) Ref-Ti at magnification $650 \times$.

the isosceles triangle with the same surface than the powder heap. This isosceles triangle corresponds to the ideal heap shape. The lower the repose angle, the better the powder flowability is [17]. The deviation between the real heap shape and the triangular heap gives the cohesive index $\sigma_{\mathrm{r}}$. The height of the powder heap $h_{\mathrm{r}}$ was also measured to be correlated with the powder flowability. A lower height corresponds to a good flowability.

2.3.2.2. Rotating drum method. The powder flow in a rotating drum is analyzed by image treatment. This instrument can be considered as a powder rheometer. A horizontal aluminum cylinder with glass side walls is half filled with $55 \mathrm{ml}$ of powder [17]. The cylinder rotates around its axis at an angular velocity ranging from $2 \mathrm{rpm}$ to $20 \mathrm{rpm}$. The rotation induces a flow of the powder. A CCD camera takes snapshots ( 50 images separated by $0.5 \mathrm{~s}$ ) for each angular velocity. The air/powder interface is detected on each snapshot with an edge detection algorithm. Afterwards, the average interface position and fluctuations around this average position are computed. For each rotating speed, the flowing angle $\alpha_{\mathrm{f}}$ is computed from the average interface position and the cohesive index $\sigma_{\mathrm{f}}$ is measured from the interface fluctuations (see Fig. 2). In addition, this method gives the opportunity to study complex rheological properties of the powders (shear thinning, shear thickening and thixotropic behavior) as a function of the shearing rates [17]. Thixotropy is evaluated by measuring the enclosed surface area between the ascending and descending flow curves (angle or cohesive index).

2.3.2.3. Tapped density method. The compaction dynamics of the powder submitted to successive taps are analyzed with a semi-automatized device. The Hausner ratios, the initial density and the final density are extracted from compaction curves [16]. The powder is placed in a metallic tube with a rigorous initialization process. Afterward, a light hollow cylinder is placed on the top of the pile to keep it flat during compaction.
The tube containing the powder sample rose up to a height of $\Delta \mathrm{Z}=3 \mathrm{~mm}$ and performs a free fall. The height $h$ of the pile is measured automatically after each tap. From the height $h$, the volume $V$ of the pile is computed (Fig. 2B). As the powder mass $\mathrm{m}$ is known, the bulk density $\rho_{\text {bulk }}$ is evaluated and plotted as a function of the tap number $n$. The bulk density is the ratio between the mass $\mathrm{m}$ and the volume $\mathrm{V}$ of the powder. The packing fraction $\eta$ is also calculated by dividing the bulk density $\rho_{\text {bulk }}$ by the true density $\rho_{\text {true }}$ of the material. The packing fraction $\eta$ corresponds to the ratio between the volume occupied by the grains and the volume of the pile. The measurements have been performed with $25 \mathrm{ml}$ of powder subjected to 500 taps [17]. The Hausner ratio is related to the compaction ratio and is calculated by the equation $\mathrm{H}_{\mathrm{r}}=\rho_{0} / \rho_{500}$, where $\rho_{0}$ is the initial bulk density and $\rho_{500}$ the bulk density after 500 taps [16]. The protocol of the improved tapped density measurement method is described in more detail in [17].

The randomly selected, representative powder samples for each $\mathrm{Ti}$ alloy were tested using the three different measuring methods. Measurements by the heap shape method were repeated 3 times for 16 heap projections since deviation between the heap interface and the ideal heap shape was distinctly different in repeated experiments for cohesive powders. For all results p-values, determined based on an ANOVA single factor test, were considered significant if smaller than 0.05. Measurements performed with the other two powder characterization methods (rotating

Table 2

EDX measurements of TNZ-1 powder showing no difference in chemical composition between spherical and non-spherical particles.

\begin{tabular}{llll}
\hline Element & wt.\% & \\
\cline { 2 - 4 } & $\mathrm{Ti}$ & $\mathrm{Nb}$ & $\mathrm{Zr}$ \\
\hline Spherical particles & $66.6 \pm 7.5$ & $18.1 \pm 4.4$ & $17.3 \pm 3.2$ \\
Non-spherical particles & $71.7 \pm 9.8$ & $17.2 \pm 5.2$ & $18.1 \pm 4.6$ \\
\hline
\end{tabular}




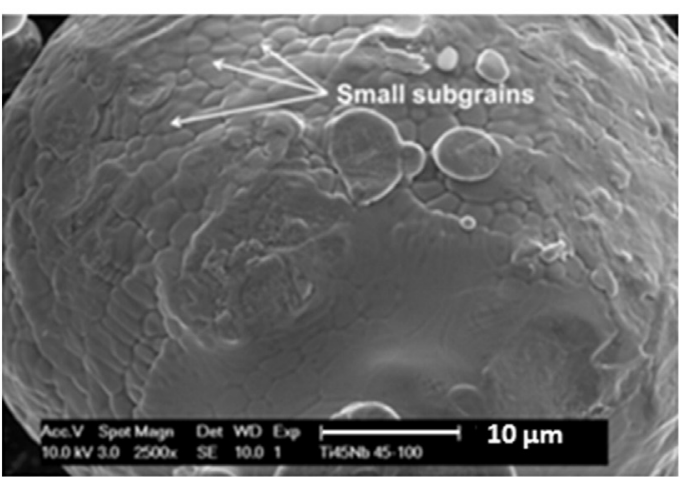

A

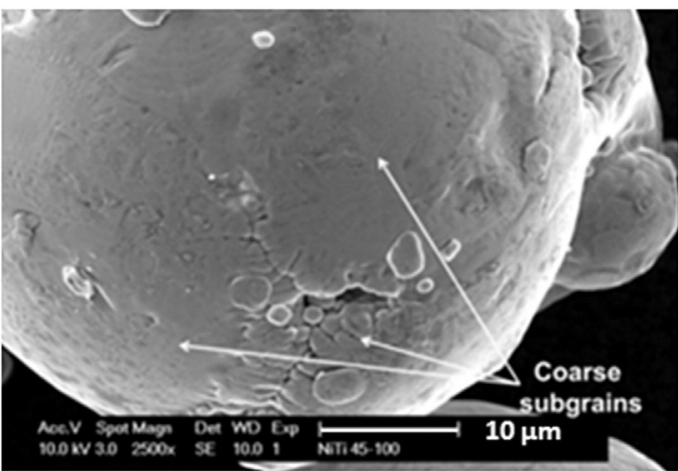

$\mathrm{C}$

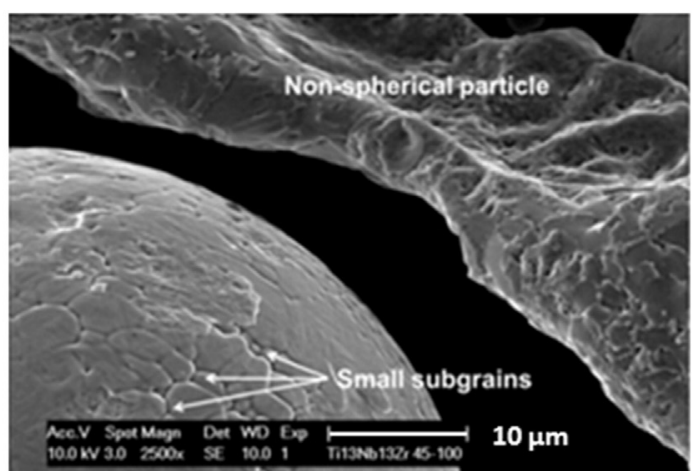

B

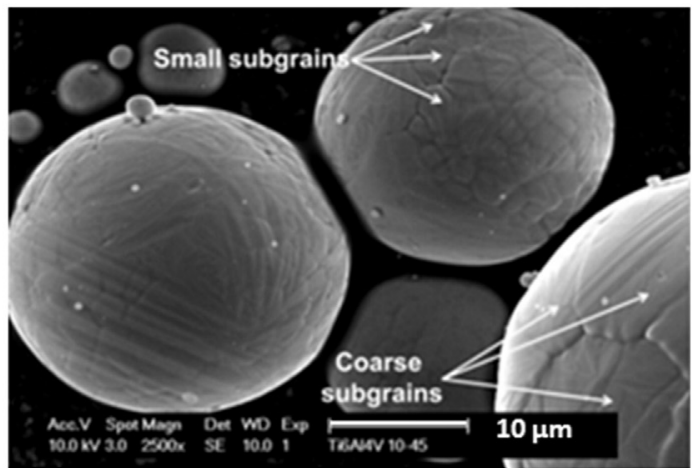

$\mathrm{D}$

Fig. 4. SEM pictures of 25-45 $\mu \mathrm{m}$ fraction powders: (A) TiNb-1, (B) TNZ-1, (C) NiTi-1 and (D) Ref-Ti at magnification 3500×.

drum method and tapped density method) were performed only once and considered as reliable referring to the value uncertainties obtained in the work of G. Lumay et al. [17].

\subsection{Powder testing for their applicability as feed powder for SLM}

A thin first layer of each of the gas atomized $\beta$-Ti powders, before and after heat treatment, was dispensed on the SLM building platform to qualitatively test uniformity of the layer and powder suitability for SLM manufacturing, in comparison to the industrial standard of plasma atomized Ti-6Al-4V powder. A polymer coater was used to spread the powder that was fed from the feed container onto the build platform (Fig. 1). Afterwards each powder layer was assessed for uniformity by the eye.

\section{Results and discussion}

\subsection{Powder synthesis and characterization}

In general, SEM imaging showed that the powder particles have a predominantly spherical shape even if, non-spherical particles or spherical imperfections were occasionally detected (Fig. 3). The significant number of non-spherical particles detected in TNZ powders is most probably caused by the processing difficulties during the gas atomization process. For instance, a decrease in the velocity of argon gas used to break up a melt stream into droplets during the gas atomization process could result in droplet spheroidization time $\left(t_{\mathrm{sph}}\right)$ longer than that of solidification $\left(t_{\mathrm{sol}}\right)$. If $t_{\mathrm{sph}}>\mathrm{t}_{\mathrm{sol}}$ solidifying droplets tend to form non-spherical particles [24].

Qualitative and semi-quantitative EDX analyses of non-spherical particles revealed a similar chemical composition to spherical ones (Table 2). For each powder sample the chemical composition of 10 particles was measured. SEM of the TiNb and TNZ powders showed a more pronounced surface topography for the majority of the particles in contrast to Ref-Ti powder (Fig. 4). Generally the surface topography of NiTi particles appeared to be closer to that of the reference powder Ref-Ti (Fig. 4C, D). The surface topography differences as seen by SEM analysis are most likely related to the shape forming techniques applied (gas and plasma atomization) [25-27] and chemical composition of the powders resulting in a different number of surface irregularities and subgrain sizes of the particles.

Nevertheless, no obvious differences in the spherical shape and surface topography were observed when qualitatively comparing NiTi

Table 3

Bulk chemical composition of the powders determined by qualitative and quantitative ICP-OES analyses.

\begin{tabular}{|c|c|c|c|c|c|c|c|c|}
\hline \multirow[t]{2}{*}{ Samples } & \multicolumn{8}{|c|}{ Composition (wt.\%) } \\
\hline & $\mathrm{Ti}$ & $\mathrm{Ni}$ & $\mathrm{Nb}$ & $\mathrm{Zr}$ & Al & V & $\mathrm{Fe}$ & $\mathrm{Hf}$ \\
\hline $\begin{array}{l}\text { TiNb-1 } \\
\text { TiNb-2 }\end{array}$ & Balance & - & $45.70 \pm 0.12$ & $0.05 \pm 0.01$ & $0.06 \pm 0.00$ & - & - & - \\
\hline $\begin{array}{l}\text { TNZ-1 } \\
\text { TNZ-2 }\end{array}$ & Balance & - & $23.15 \pm 0.44$ & $10.30 \pm 0.15$ & $0.14 \pm 0.00$ & - & $0.07 \pm 0.00$ & $0.19 \pm 0.00$ \\
\hline $\begin{array}{l}\text { NiTi-1 } \\
\text { NiTi-2 }\end{array}$ & Balance & $55.25 \pm 0.26$ & $3.42 \pm 0.05$ & & $0.03 \pm 0.00$ & - & $0.22 \pm 0.00$ & - \\
\hline Ref-Ti & Balance & - & - & - & $6.01 \pm 0.12$ & $3.69 \pm 0.06$ & $0.15 \pm 0.00$ & - \\
\hline
\end{tabular}


Table 4

Particle size-volume concentration ( $\mu \mathrm{m})$ measured by laser diffraction analysis in a dispersed state in liquid.

\begin{tabular}{lllrl}
\hline & $\mathrm{D}_{0.1}$ & \multicolumn{1}{l}{$\mathrm{D}_{0.5}$} & \multicolumn{1}{c}{$\mathrm{D}_{0.9}$} & \multicolumn{1}{l}{ Span } \\
\hline TiNb-1 & $14.84 \pm 0.15$ & $29.56 \pm 0.30$ & $50.36 \pm 0.50$ & $1.20 \pm 0.01$ \\
TiNb-2 & $41.43 \pm 0.41$ & $69.94 \pm 0.70$ & $108.89 \pm 1.09$ & $0.96 \pm 0.01$ \\
TNZ-1 & $18.56 \pm 0.19$ & $32.35 \pm 0.32$ & $55.70 \pm 0.56$ & $1.15 \pm 0.01$ \\
TNZ-2 & $43.44 \pm 0.43$ & $71.63 \pm 0.72$ & $110.98 \pm 1.10$ & $0.94 \pm 0.01$ \\
NiTi-1 & $15.08 \pm 0.15$ & $32.84 \pm 0.33$ & $66.21 \pm 0.66$ & $1.56 \pm 0.02$ \\
NiTi-2 & $43.04 \pm 0.43$ & $67.97 \pm 0.67$ & $103.57 \pm 1.04$ & $0.89 \pm 0.01$ \\
Ref-Ti & $13.61 \pm 0.14$ & $30.46 \pm 0.30$ & $52.43 \pm 0.52$ & $1.27 \pm 0.01$ \\
\hline
\end{tabular}

Table 5

Static properties of the powders measured by the heap shape analysis method: angle of repose $\left(\alpha_{\mathrm{r}}\right)$, cohesive index $\left(\sigma_{\mathrm{r}}\right)$ and heap height $\left(\mathrm{h}_{\mathrm{r}}\right)$.

\begin{tabular}{lccll}
\hline Samples & $\alpha_{\mathrm{r}}\left(^{\circ}\right)$ & $\sigma_{\mathrm{r}}($ a.u. $)$ & $\mathrm{h}_{\mathrm{r}}(\mathrm{mm})$ & Flow property $[16,28]$ \\
\hline TiNb-1 & $56.12 \pm 2.57$ & $3.7 \pm 1.7$ & $27.2 \pm 0.8$ & Very poor \\
TiNb-2 & $46.4 \pm 0.81$ & $0.7 \pm 0.1$ & $20.7 \pm 0.4$ & Poor \\
TNZ-1 & $53.1 \pm 1.9$ & $1.4 \pm 0.3$ & $25.6 \pm 2.1$ & Poor \\
TNZ-2 & $42.88 \pm 1.07$ & $0.5 \pm 0.1$ & $20.6 \pm 0.6$ & Passable \\
NiTi-1 & $57.6 \pm 2.55$ & $2.7 \pm 0.8$ & $29.4 \pm 1.5$ & Very poor \\
NiTi-2 & $34.28 \pm 0.41$ & $0.3 \pm 0.2$ & $14.7 \pm 0.4$ & Good \\
Ref-Ti & $38.21 \pm 1.45$ & $0.4 \pm 0.1$ & $16.5 \pm 0.4$ & Good \\
\hline
\end{tabular}

versus Ref-Ti powder, as well as TiNb versus TNZ powder. Therefore, it is unlikely that these minor differences in powder surface topography are the main contributing factor influencing powder flowability.

The bulk composition of the powders was analyzed by ICP-OES as shown in Table 3. The fact that the chemical powder composition determined by ICP-OES deviated from the theoretical values could be attributed to the effect of the gas atomization process itself [28].

As shown in Table 4, the particle size distribution of TiNb-2, NiTi-2 and Ref-Ti powders falls within the expected particle size range. For powders NiTi-1, TiNb-1, TNZ-1 and TNZ-2 the presence of smaller and bigger particles which are outside the expected range was detected (see size-volume concentration values, $\mathrm{D}_{0.1}$ and $\mathrm{D}_{0.9}$ ). This could be explained by particle agglomeration during laser diffraction measurements [29].

The static powder behavior for each random powder sample was determined by the heap shape method. The measurement results and the empirical relation with the flowability $[17,30]$ are summarized in Table 5. It can be observed that TiNb-2, TNZ-2 and NiTi-2 powders corresponding to the coarse-sized fraction $(45-100 \mu \mathrm{m})$ are non-cohesive with $\sigma_{\mathrm{r}}$ close to zero and $\alpha_{\mathrm{r}}$ in the range $34.1-46.3^{\circ}$. At the opposite, fine-sized fraction powders are characterized by both a higher cohesive index ( $\sigma_{\mathrm{r}}$ in the range 1.4-3.7 a.u.) and a higher angle of repose $\left(\alpha_{\mathrm{r}}\right.$ in the range $53.1-57.5^{\circ}$ ). Indeed, when the grains are smaller (typically smaller than $50 \mu \mathrm{m}$ ), the cohesive forces play a dominant role. The cohesive force strength is directly correlated with the cohesive index $\sigma_{\mathrm{r}}$ [17]. The cohesive forces are also known to stabilize heaps with higher angles of repose $\alpha_{\mathrm{r}}$. Fig. 5 shows the relationship between the size of the smaller particles $\mathrm{D}_{0.1}$ and the angle of repose. The correlation confirms the previous statements with one exception. Indeed, Ref-Ti powder doesn't fall within this correlation due to its specific surface properties related to plasma-atomization $[15,17]$. Ref-Ti is characterized by a very low cohesive index despite its size fraction below $45 \mu \mathrm{m}$. This behavior can be explained by the technique used for particle production. M.N. Ahsan et al. [25] found that the flowability of Ti-6Al-4V powders can be greatly enhanced by using a plasma atomization process instead of gas atomization [25,26]. Plasma atomization processing is known to produce perfect spherical-shaped powders. Indeed, hot argon gas used in the plasma atomization process allows particles to stay for a longer period at high temperature which results in a smoother particle surface than in a gas atomization process [21]. In the same sense T. Marcu et al. stated that thermal treatment of Ti-6Al-7Nb powder at $500{ }^{\circ} \mathrm{C}$ during $1 \mathrm{~h}$ in air improves its flowability by the formation of an $\mathrm{Al}_{2} \mathrm{O}_{3}$ surface layer on the particles [13].

Fig. 6 shows the evolution of the cohesive index obtained using the rotating drum method as a function of the rotating speed for both powder fractions. The measurements have been performed with an increasing rotating speed (from 2 to $20 \mathrm{rpm}$ ) followed by a decreasing rotating speed (from 20 to $2 \mathrm{rpm}$ ). Therefore, the powder thixotropy is evaluated. To improve the clarity of the plot, the cohesive index is plotted only for increasing rotating speed. The results extracted from these rheological curves are summarized in Table 6. In agreement with the results from heap shape analysis, the coarse-sized fractions are less cohesive than the fine-sized fractions. Moreover, the coarse-sized fractions show a low thixotropy (see Table 6). The better rheological behavior of the powder sample NiTi- 2 is confirmed by the low value of the flowing angle $\alpha_{\mathrm{f}}$, of the cohesive index $\sigma_{\mathrm{f}}$ and of the thixotropy. The flowing properties of NiTi-2 powder are more stable under motion than those

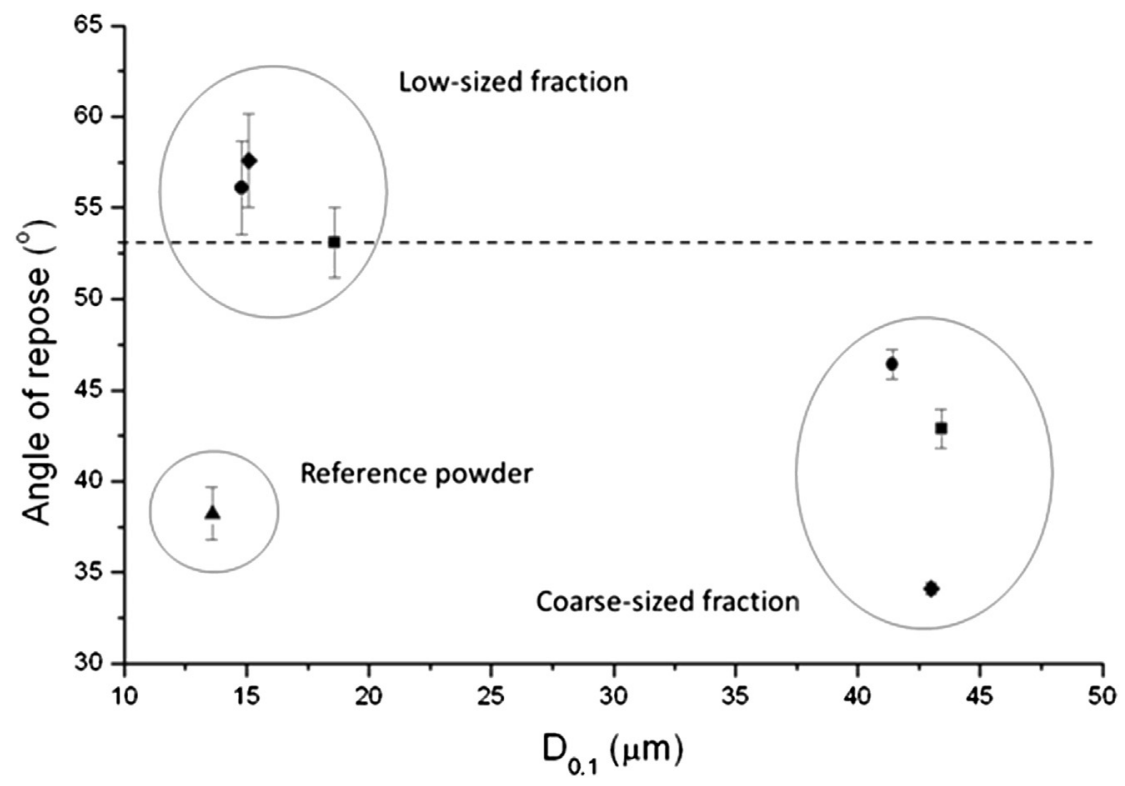

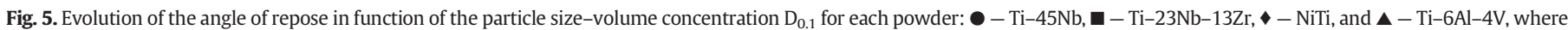
dashed line corresponds to the upper threshold below which successful SLM processing is possible. 


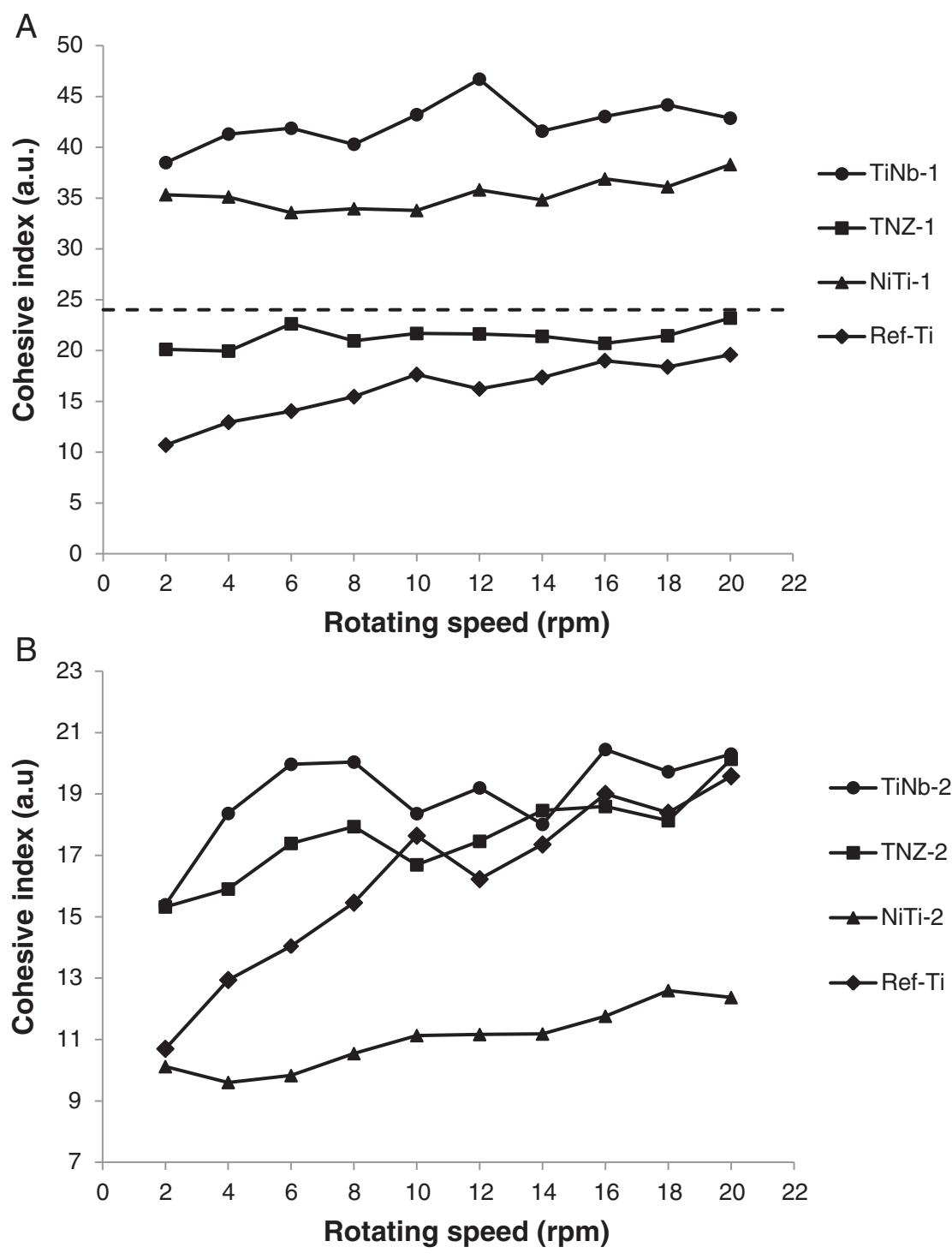

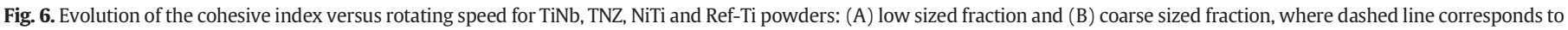
the upper threshold below which successful SLM processing is possible.

of powder Ref-Ti. Indeed, the cohesive index of NiTi-2 doesn't significantly depend on the rotating speed. In contrast the cohesive index of Ref-Ti powder increases proportionally to the rotating speed and thus demonstrates shear thickening behavior (Fig. 6B).

Table 6

Summary of the dynamic (flowing angle $\alpha_{\mathrm{f}}$, cohesive index $\sigma_{\mathrm{f}}$ and thixotropy) and semidynamic (initial packing fraction $\eta_{0}$, final packing fraction $\eta_{500}$, Hausner ratio $\mathrm{H}_{\mathrm{r}}$ ) rheological characteristics measured for the random sample of each Ti-powder batch. The last two columns show the applicability for SLM process.

\begin{tabular}{|c|c|c|c|c|c|c|c|c|}
\hline \multirow[t]{2}{*}{ Samples } & \multicolumn{3}{|l|}{ Flow } & \multicolumn{3}{|c|}{ Density } & \multicolumn{2}{|c|}{ SLM applicability } \\
\hline & $\begin{array}{l}\alpha_{\mathrm{f}}\left({ }^{\circ}\right) \\
\text { at } 6 \mathrm{rpm}\end{array}$ & $\begin{array}{l}\sigma_{\mathrm{f}} \text { at } \\
6 \mathrm{rpm}\end{array}$ & Thixotropy & $\eta_{0}$ & $\eta_{00}$ & $\mathrm{H}_{\mathrm{r}}$ & $\begin{array}{l}\text { First layer } \\
\text { uniformity }\end{array}$ & $\begin{array}{l}\text { Ability to } \\
\text { build parts }\end{array}$ \\
\hline TiNb-1 & 51.2 & 38.4 & 36.2 & 0.51 & 0.62 & 1.15 & - & - \\
\hline TiNb-2 & 36.3 & 19.9 & 18.6 & 0.56 & 0.64 & 1.12 & + & + \\
\hline TNZ-1 & 37.3 & 22.6 & 18.9 & 0.52 & 0.63 & 1.15 & - & + \\
\hline TNZ-2 & 35.4 & 17.4 & 11.2 & 0.53 & 0.64 & 1.16 & + & + \\
\hline NiTi-1 & 41.1 & 33.6 & 41.0 & 0.53 & 0.63 & 1.13 & - & - \\
\hline NiTi-2 & 29.0 & 9.8 & 10.0 & 0.58 & 0.65 & 1.10 & + & + \\
\hline $\mathrm{R}$ & 32.5 & 14.0 & 11.4 & 0.61 & 0.69 & 1.10 & + & + \\
\hline
\end{tabular}

For the fine-sized fraction, it can be observed that the Ref-Ti powder displays the best flow properties. Powder TNZ-1 shows acceptable cohesive index values. However, both TiNb-1 and NiTi- 1 powders have high cohesive index values (Table 6 ). The differences in terms of cohesion between powder TNZ-1 and powders NiTi-1 and TiNb-1 cannot be attributed only to the particle size and surface topography (Table 4 and Fig. 4), as these powders have similar particle size and surface characteristics. Hence, the main differences most likely stem from both surface composition and particle shape. Concerning the particle shape, the sample TNZ-1 is a mix of spherical and irregular particles (Fig. 3). At the opposite, NiTi-1 and TiNb-1 grains are mainly spherical. Irregular particles can have a negative effect on the powder flowability [31,32]. Indeed, the presence of irregular and elongated particles increases the friction between the grains and the number of inter-particle contacts. In the present case, the expected negative influence of irregular particles is not visible, thus the relatively low cohesive index of powder TNZ-1 is most likely attributed to its chemical surface composition. In particular, the presence of zirconium oxide(s) on the particle surface [33] was detected by XPS measurement (data not shown).

The results of the tapped density analysis are summarized in Table 6. Initial and final packing fractions are always higher for the coarse-sized 


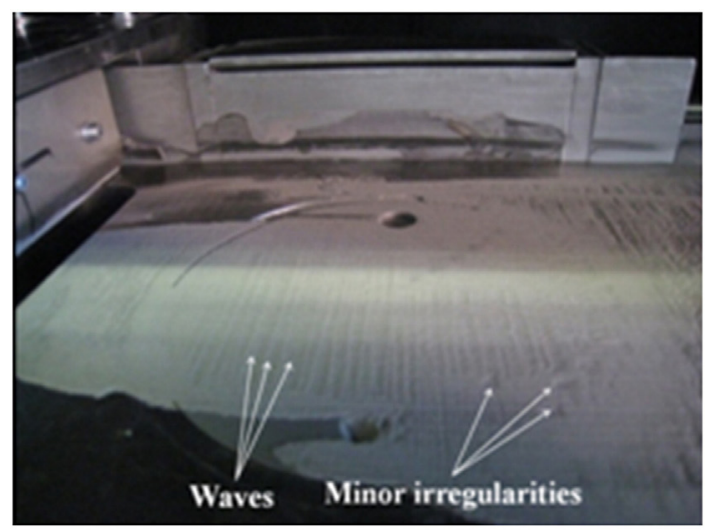

A

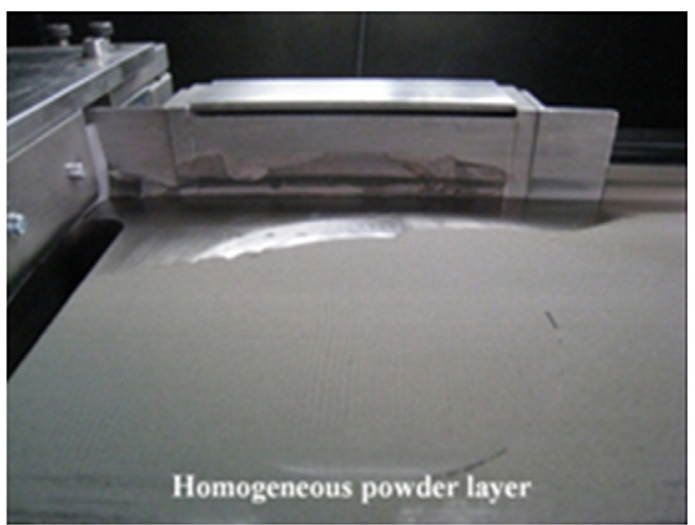

B

Fig. 7. Deposition of the first powder layer on the SLM building platform of (A) TNZ-1 and (B) TNZ-2 powders.

than for the fine-sized fraction. This can be related to the limited cohesion forces between the particles observed for coarse size fractions (Table 5). However, the Hausner ratio does not clearly allow classification of the powders as all of them can be considered as having an excellent or at least a good flowing property [30].

The static, semi-dynamic and dynamic physical properties of the powders are directly related to the powder layer uniformity on the SLM building platform (Tables 5, 6). Powders of the fine-sized fraction $(<45 \mu \mathrm{m})$, except Ref-Ti, deposited on the SLM building platform demonstrated generally poor flowing properties. In particular, with as-produced TiNb-1 powder, it was not possible to provide a homogeneous first layer. This confirmed the results obtained with both heap shape and rotating drum methods giving the highest static and dynamic cohesive indexes for TiNb-1 powder. However, as-received TNZ-1 and Ref-Ti powders could be distributed without any further pretreatment. Nevertheless, it is worth mentioning that minor irregularities (waves) of powder can be noticed in the layer of TNZ-1 (Fig. 7A) indicating insufficient powder flowability that may lead to inhomogeneous temperature distribution and occurrence of pores during the build-up of SLM parts. As a result, process stability regarding dimensional accuracy

\section{Table 7}

Comparison of the static rheological properties obtained by heap shape method of TiNb-1 powder before and after heat treatment in air at $600^{\circ} \mathrm{C}$ during $1 \mathrm{~h}$ and commercially available Ref-Ti powder.

\begin{tabular}{|c|c|c|c|c|}
\hline \multirow[t]{2}{*}{ Samples } & \multicolumn{2}{|c|}{ Before heat treatment } & \multicolumn{2}{|c|}{ After heat treatment } \\
\hline & $\alpha_{\mathrm{r}}\left({ }^{\circ}\right)$ & $\sigma_{\mathrm{r}}($ a.u. $)$ & $\alpha_{\mathrm{r}}\left({ }^{\circ}\right)$ & $\sigma_{\mathrm{r}}($ a.u. $)$ \\
\hline TiNb-1 & $57.5 \pm 1.2$ & $3.7 \pm 1.7$ & $50.7 \pm 1.0$ & $0.7 \pm 0.1$ \\
\hline Ref-Ti & $38.21 \pm 1.45$ & $0.4 \pm 0.1$ & - & - \\
\hline
\end{tabular}

required for good SLM processing may be too limited [34]. At the same time, according to the static, semi-dynamic and dynamic rheological analyses, flowability of the TNZ-1 powder was found to be the highest among the fine $\beta$-Ti powder fraction but remained lower than those of the commercial Ref-Ti powder. Thus it is worth to assume that a powder with an angle of repose $\left(\alpha_{\mathrm{r}}\right)$ higher than $53^{\circ}$, cohesive index $\left(\sigma_{\mathrm{r}}\right)$ higher than 1.4 in the case of static rheological analysis, an avalanche angle $\left(\alpha_{\mathrm{f}}\right)$ higher than $37^{\circ}$, and a cohesion index $\left(\sigma_{\mathrm{f}}\right)$ about 22 in the case of dynamic rheological analysis will lead to the formation of waves in the powder layer on the SLM build platform. Dashed lines in Figs. 5 and $6 \mathrm{~A}$ indicate an approximate minimum performance limit required for successful SLM processing. NiTi-2 is characterized by the best static and dynamic rheological behavior among the coarse $\beta$-Ti powder fraction (Tables 5-6; Fig. 7B). However, for the coarse powder fraction, all powders could be deposited without any problem on the SLM building platform (Fig. 7B). Therefore, no clear differences in powder layer homogeneity for the powders of the coarse powder fraction could be seen (data not shown). These results conform to previous works on the successful SLM processing of NiTi and Ti-24Nb-4Zr-8Sn powders [35-37] having particle sizes larger than $45 \mu \mathrm{m}$. Thus, newly developed semi-automatic techniques have proven their relevance for the assessment of static and dynamic rheological properties of the powders intended for AM applications.

\subsection{Thermal treatment of $\mathrm{Ti}-45 \mathrm{Nb}$ powder}

The $\beta$-Ti powders with a spherical shape were classified into two groups as a function of their particle size. The powders with a particle size lower than $45 \mu \mathrm{m}$ have limited flow characteristics and those with a particle size between 45 and $100 \mu \mathrm{m}$ display a more acceptable rheological behavior.

The Ref-Ti commercial powder on the other hand, with a similar particle size distribution as the other powders of the fine fraction (TiNb-1, TNZ-1, NiTi-1), stands out of this classification, which may be explained by its plasma instead of gas atomization production method. This should be attributed to a smoothing of the surface of the formed particles due to a longer stay at elevated temperature during the plasma atomization process $[25,26]$. Thus, the use of plasma-atomized powders instead of gas-atomized is more advisable for SLM applications.

To improve powder flowability spheroidizing by a plasma induction treatment is often used [27]. However, owing to the high cost of this technology priority was given to a heat treatment approach. Thus, TiNb-1 powder was exposed to a heat treatment (at $600{ }^{\circ} \mathrm{C}$ for $1 \mathrm{~h}$ ) in air and to the same heat treatment but in argon atmosphere [13]. The heat treatment in air might induce formation of a thicker oxide layer on the particle surface and a slight smoothing of the particle surface but most likely will also result in diffusion of interstitial impurity atoms such as $\mathrm{O}$ and $\mathrm{N}$, which might compromise quality when high strength and ductility of fabricated parts are required [38].

As shown by Table 7, the powder subjected to heat treatment in air was characterized by a lower cohesive index $(0.7 \pm 0.1$ in comparison to $3.7 \pm 1.7$ respectively) and a lower angle of repose (50.7 \pm 1.0 in comparison to $57.5 \pm 1.2$ respectively) (Table 7). These values confirm utterly different behaviors of TiNb-1 powder deposited on the SLM building platform prior to and after applied heat treatment. It was not possible to provide a homogeneous first layer using as-produced powder. Nevertheless, TiNb-1 powder subjected to a heat treatment either in air or argon atmosphere (at $600^{\circ} \mathrm{C}$ during $1 \mathrm{~h}$ ) demonstrates uniform spreading on the build platform in SLM machine (Fig. 10A, B).

The rotating drum data (Fig. 8) indicates that flow curves of the TiNb-1 heat treated samples are considerably lower than those measured for the non-heat treated samples. Moreover, the flow curve of the TiNb-1 sample heat treated in argon even nearly overlaps with the flow curve of the Ref-Ti showing lower dynamic cohesive index in comparison to the TiNb-1 sample heat-treated in air. 


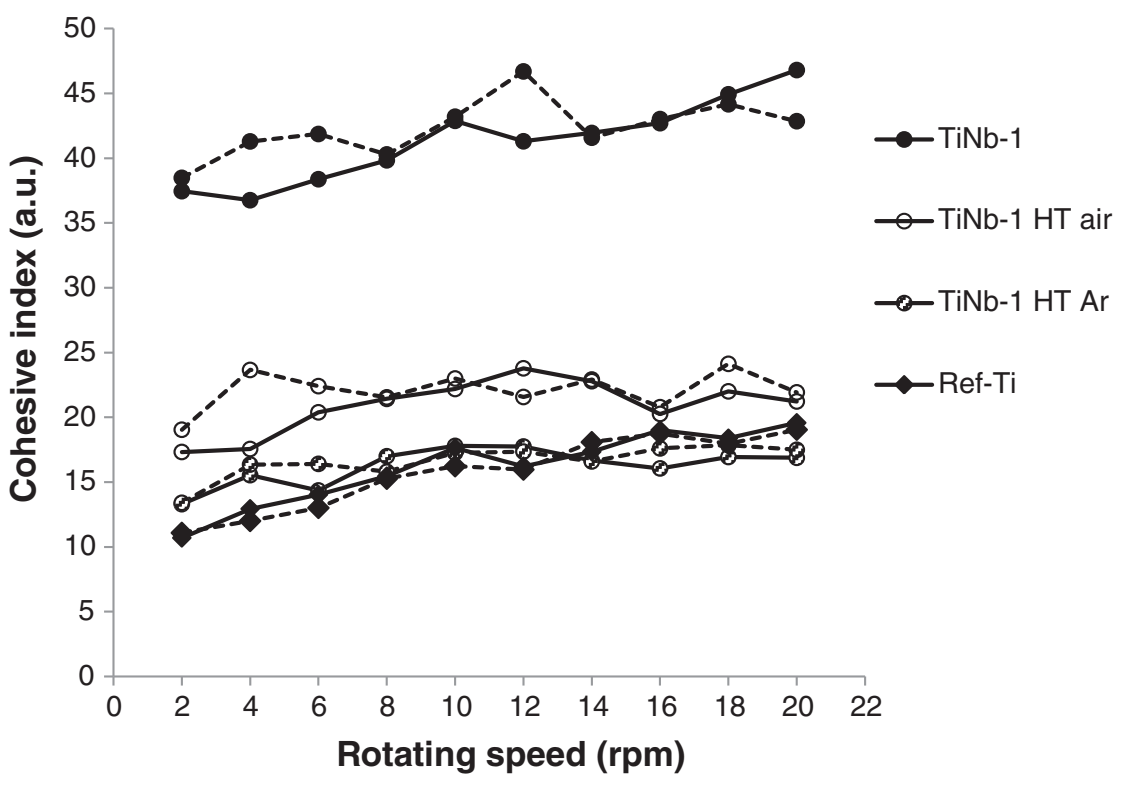

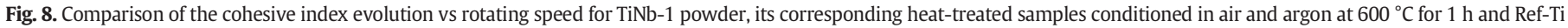
powder, where solid line corresponds to ascending curve and dash line to descending curve.

While both heap shape and rotating drum analyses confirmed the above-mentioned hypotheses concerning improvement of the flowing properties of the heat treated TiNb-1 powder, the tapped density analysis didn't clearly allow to judge about the effect of heat treatment in air on the rheological behavior. Table 8 compares the packing fraction of the as-produced TiNb-1 powder and its corresponding heat-treated batch. Initial packing fractions of the powder heat-treated in air were lower while final packing fractions were higher compared to the nonheat treated powder. Thus, the tapped density analysis technique is not sufficient for establishing a good classification of the powders.

Whereas SEM analysis of the TiNb-1 air heat treated powder showed a smoother surface topography for the majority of the particles, the argon heat treated powder TiNb-1 showed only a slight additional smoothening of its surface in comparison to as-received gas atomized powder (Fig. 9). Nevertheless, TiNb-1 heat treated in argon also demonstrated improved flowing properties by GranuDrum analysis (Fig. 8) and while being dispensed by a coater during SLM processing in comparison to non-heat treated TiNb-1 powders (Fig. 10). Therefore the improvement of flowability for the heat treated TiNb-1 powder cannot only be attributed to a surface smoothening or to the formation of a thicker oxide layer for the TiNb-1 sample heat treated in air [13] and a change in surface chemical composition [39]. Another reason for the differences in flowability could be the formation of a suboxide within the oxide film in addition to abundant $\mathrm{TiO}_{2}$ [40] and could also be the conversion of amorphous anatase to rutile at the annealing temperatures in the range of $500-1000{ }^{\circ} \mathrm{C}[41,42]$. However, to confirm the above-mentioned assumptions detailed XPS analysis of Ti oxidation states is needed.

\section{Conclusions}

Rheological properties of three gas-atomized $\beta$-Ti powders (Ti-45Nb, Ti-23Nb-10Zr and NiTi) as raw material for Selective Laser Melting (SLM) have been studied and compared to those of the industrial SLM reference, being plasma atomized Ti-6Al-4V. For all powders the coarse fraction (45-100 $\mu \mathrm{m})$ revealed very good flowing properties in contrast to those of the fine fraction $(<45 \mu \mathrm{m})$, for which only the reference Ti-6Al-4V powder maintained good flow properties. For the gas atomized $\beta-\mathrm{Ti}$ alloy powders the principal tendency was followed that the flow behavior of particles being less than $50 \mu \mathrm{m}$ in size is mainly influenced by cohesive forces. The superior flowability of the reference Ti-6Al-4V powder is attributed to the plasma atomization technique that allowed a prolonged stay of the particles at an elevated temperature.

The gas atomization process resulted as expected in spherical powders, except for Ti-23Nb-10Zr which contained also irregular-shaped particles of the same chemical composition. Irregular shaped particles are known to increase cohesive forces between particles. Nevertheless, Ti-23Nb-10Zr powder represented the best rheological properties for the fine-sized fraction powders and NiTi for the coarse-sized fraction powders. The flowability of the Ti-45Nb powder was the least for both fractions, partially related to the attachment of satellites to the larger grains.

With regard to SLM manufacturing it was concluded that the flowability characteristics of $\mathrm{Ti}-45 \mathrm{Nb}$ powder (fine fraction) were insufficient to produce reference samples by SLM. To improve its rheological properties the powder was subjected to annealing at $600{ }^{\circ} \mathrm{C}$ for $1 \mathrm{~h}$ in argon and air atmosphere. Annealed samples of TiNb-1 powder displayed an improved flowability behavior and enabled SLM processing. Flowability characteristics of Ti-23Nb-10Zr powder (fine fraction) did not also allow a completely homogeneous distribution of powder layer in the SLM machine required for a good dimensional accuracy of SLM parts, however, enabled the build-up process. Thus rheological properties of $\mathrm{Ti}-23 \mathrm{Nb}-10 \mathrm{Zr}$ powder are close to a minimum required performance limit below which successful SLM processing is possible. Future investigation will involve detailed XPS study for a better interpretation of the obtained results.

Table 8

Comparison of the initial $\left(\eta_{0}\right)$ and final $\left(\eta_{500}\right)$ packing fractions of TiNb-1 powder before and after heat treatment in air at $600{ }^{\circ} \mathrm{C}$ during $1 \mathrm{~h}$.

\begin{tabular}{|c|c|c|c|c|c|c|}
\hline \multirow[t]{2}{*}{ Samples } & \multicolumn{2}{|c|}{$\begin{array}{l}\text { Before heat } \\
\text { treatment }\end{array}$} & \multirow[t]{2}{*}{ First layer uniformity in SLM machine } & \multicolumn{2}{|c|}{ After heat treatment } & \multirow[t]{2}{*}{ First layer uniformity in SLM machine } \\
\hline & $\eta_{0}$ & $\eta_{00}$ & & $\eta_{0}$ & $\eta_{00}$ & \\
\hline TiNb-1 & 0.54 & 0.62 & - & 0.47 & 0.65 & + \\
\hline
\end{tabular}




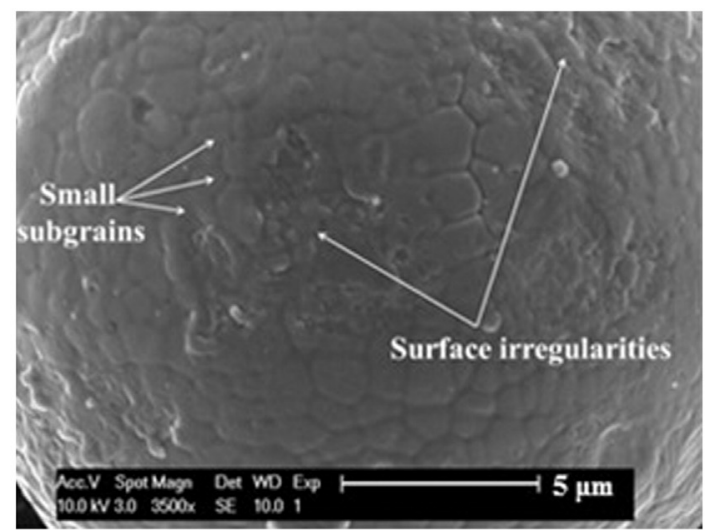

A

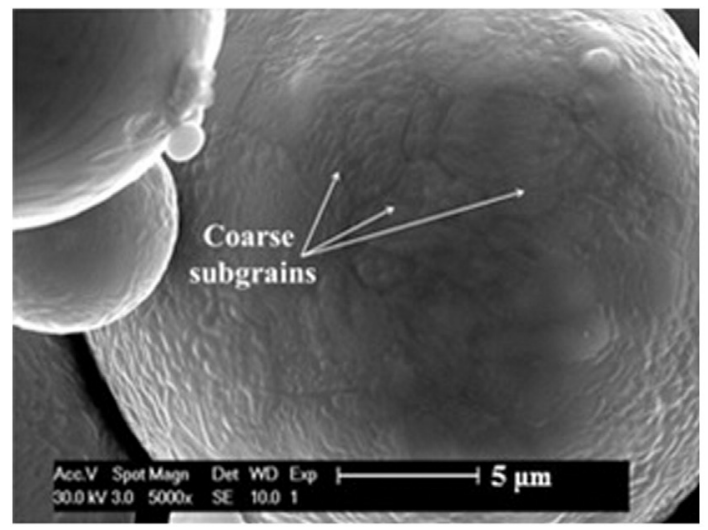

B

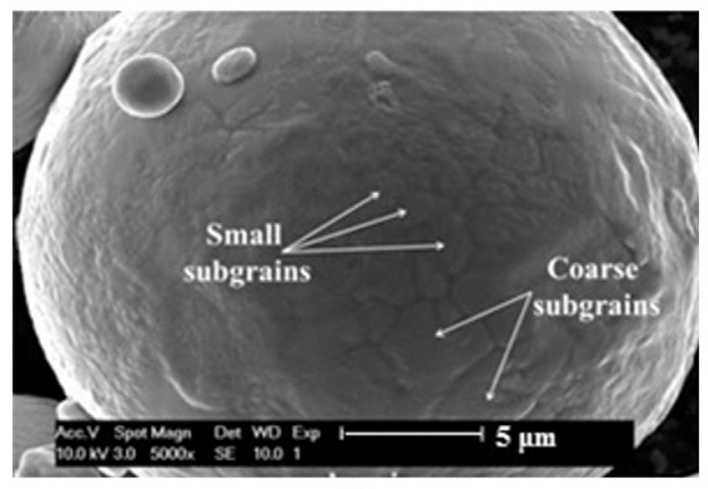

$\mathrm{C}$

Fig. 9. SEM pictures of (A) TiNb-1, (B) TiNb-1 after heat treatment in air at $600{ }^{\circ} \mathrm{C}$ for $1 \mathrm{~h}$, and $(\mathrm{C})$ TiNb-1 after heat treatment in argon at $600{ }^{\circ} \mathrm{C}$ for $1 \mathrm{~h}$.

This study proves the relevance of new semi-automatic analyses based on the heap shape, rotating drum and tapped density methods for rheological analysis of the powders intended for SLM processing.

\section{Acknowledgments}

The authors acknowledge I. Thijs and S. Mullens of VITO, Mol, Belgium for the particle size distribution analysis by Laser Diffraction and support within the EU 7th framework program (FP7) under Marie Curie ITN project BioTiNet (grant no. 264635).

\section{References}

[1] T. Danesh-Clough, S. MacDonald, Indications for revision total hip arthroplasty, in: D. Berry, R. Trousdale, D. Dennis, W. Paprosky (Eds.), Revision Total Hip and Knee Arthroplasty, Lippincott Williams \& Wilkins, Philadelphia 2012, pp. 65-76.

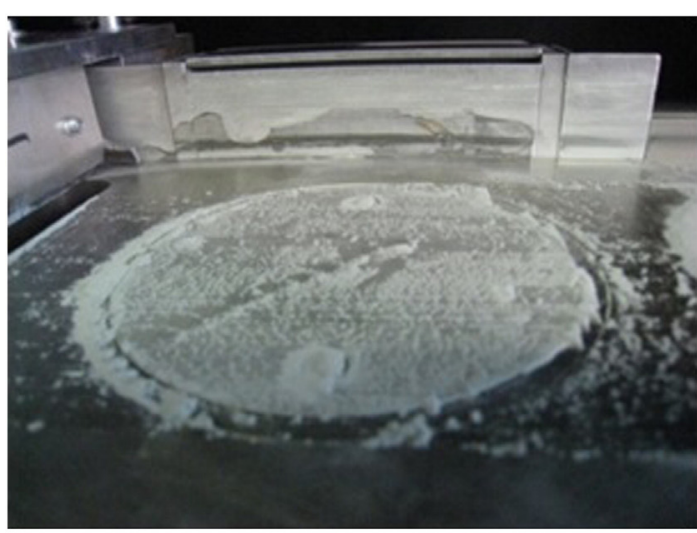

A

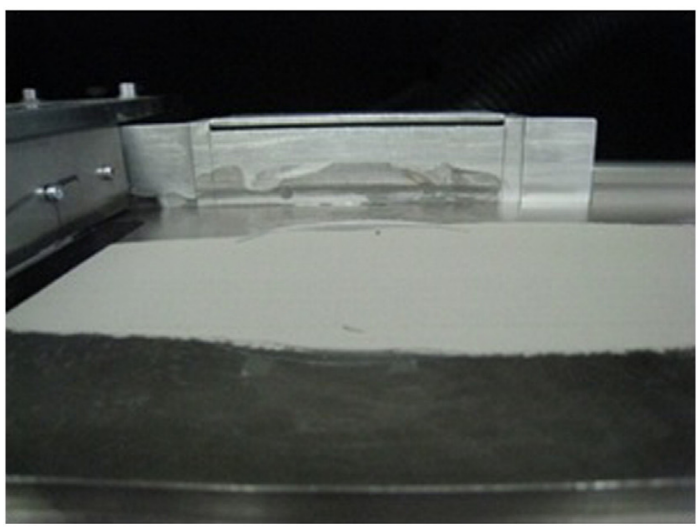

B

Fig. 10. Deposition of the first powder layer on the SLM building platform of (A) TiNb-1 as-produced and (B) TiNb-1 heat treated in argon at $600{ }^{\circ} \mathrm{C}$ for $1 \mathrm{~h}$.

[2] M.I.Z. Ridzwan, S. Shuib, A.Y. Hassan, A.A. Shokri, M.N.M. Ibrahim, Problem of stress shielding and improvement to the hip implant designs: a review, J. Med. Sci. 7 (2007) 460-467.

[3] G. Ryan, A. Pandit, D.P. Apatsidis, Fabrication methods of porous metals for use in orthopaedic applications, Biomaterials 27 (2006) 2651-2670.

[4] L.E. Murr, S.M. Gaytan, E. Martinez, F. Medina, R.B. Wicker, Next generation orthopaedic implants by additive manufacturing using electron beam melting, Int. J. Biomater. 2012 (2012) 1-14.

[5] S. Van Bael, G. Kerckhofs, M. Moesen, G. Pyka, J. Schrooten, J.-P. Kruth, MicroCT-based improvement of geometrical and mechanical controllability of selective laser melted Ti6Al4V porous structures, Mater. Sci. Eng. 528 (2011) 7423-7431.

[6] P.H. Warnke, T. Douglas, P. Wollny, E. Sherry, M. Steiner, S. Galonska, S.T. Becker, I.N. Springer, J. Wiltfang, S. Sivananthan, Rapid prototyping: porous titanium alloy scaffolds produced by selective laser melting for bone tissue engineering, Tissue Eng. C. 15 (2009) 115-124.

[7] J. Wieding, A. Jonitz, R. Bader, The effect of structural design on mechanical properties and cellular response of additive manufactured titanium scaffolds, Materials 5 (2012) 1336-1347.

[8] D. Leordean, T. Marcu, S.A. Radu, P. Berce, Porous metal structures from Ti alloys produced by SLM technology, Acad. J. Manuf. Eng. 9 (2011) 10-15.

[9] S. Rao, T. Ushida, T. Tateishi, Y. Okazaki, S. Asao, Effect of Ti, Al, and V ions on the relative growth rate of fibroblasts (L929) and osteoblasts (MC3T3 E1) cells, Biomed. Mater. Eng. 6 (1996) 79-86.

[10] P.R. Walker, J. Leblanc, M. Sikorska, Effects of aluminum and other cations on the structure of brain and liver chromatin, Biochemistry 28 (1989) 3911-3915.

[11] M. Niinomi, Biologically and mechanically biocompatible titanium alloys, Mater. T. 49 (2008) 2170-2178.

[12] J.-P. Kruth, G. Levy, F. Klocke, T.H.C. Childs, Consolidation phenomena in laser and powder-bed based layered manufacturing, CIRP Ann. Mfg Technol. (2007) 730-759.

[13] T. Marcu, M. Todea, I. Gligor, P. Berce, C. Popa, Effect of surface conditioning on the flow ability of Ti6Al7Nb powder for selective laser melting applications, Appl. Surf. Sci. 258 (2012) 3276-3282

[14] S. Shabalovskaya, J. Anderegg, J. Van Humbeeck, Critical overview of nitino surfaces and their modification for medical applications, Acta Biomater. 4 (2008) 447-467.

[15] N. Vlachos, I.T.H. Chang, Investigation of flow properties of metal powders from narrow particle size distribution to polydisperse mixtures through an improved Hallflowmeter, Powder Technol. 205 (2011) 71-80. 
[16] K. Traina, R. Cloots, S. Bontempi, G. Lumay, N. Vandewalle, F. Boschini, Flow abilities of powders and granular materials evidenced from dynamical tap density measurement, Powder Technol. 235 (2013) 832-842.

[17] G. Lumay, F. Boschini, K. Traina, S. Bontempi, J.-C. Remy, R. Cloots, N. Vandewalle, Measuring the flowing properties of powders and grains, Powder Technol. 224 (2012) 19-27.

[18] D. Schulze, Round robin test on ring shear testers, Adv. Powder Technol. 22 (2011) 197-202.

[19] R. Freeman, Measuring the flow properties of consolidated, conditioned and aerated powders - a comparative study using a powder rheometer and a rotational shear cell, Powder Technol. 174 (2007) 25-33.

[20] D. Goehler, TLS - The ProcessTls-technik.de. Available at: http://www.tls-technik. de/e_2.html2014 (Accessed 14 Sep. 2014).

[21] J. Kroeger, F. Marion, Raymor AP\&C: leading the way with plasma atomised Ti spherical powders for MIM, PIM Int. 5 (2011) 55-57.

[22] Anon, Available at: http://www.malvern.com/en/products/product-range/mastersizerrange/mastersizer-2000/default.aspx2014 (Accessed 14 Sep. 2014).

[23] Anon, Available at: http://iconsteel.net/images/Varian_720_730_ Specifications. pdf2014 (Accessed 14 Sep. 2014)

[24] O.S. Nichiporenko, Y.I. Naida, Heat exchange between metal particles and gas in the atomization process, Soviet Powder Metall. Ceram. 7 (1968) 509-512.

[25] M.N. Ahsan, A.J. Pinkerton, R.J. Moat, J. Shackleton, A comparative study of laser direct metal deposition characteristics using gas and plasma atomized Ti-6Al-4V, Mater. Sci. Eng. A 528 (2011) 7648-7657.

[26] T. Whitton, Plasma atomization: a unique process for production high purity biomedical powders with exceptional sphericity, BoneZone 6 (2005) 97-98.

[27] M. Boulus, Plasma power can make better powders, Met. Powder Rep. 59 (2004) 16-21.

28] G.R. Zbigniew, P. Bandola, T. Skubiszewski, Argon-shielded hot pressing of titanium alloy (Ti6Al4V) powders, Acta Bioeng. Biomech. 12 (2010) 41-46.

[29] Shimadzu Corporation, SALD-2300 Laser Diffraction Particle Size Analyzer|Top: SHIMADZU (Shimadzu Corporation), Available at: http://www.shimadzu.com/an/ powder/sald2300/2300.html, 2014, (Accessed 14 Sep. 2014).

[30] European pharmacopoeia 7.0, chapter 2.9.36, Powder flow (2010) 308
[31] B. Sustarsic, M. Godec, M. Jenko, T. Drglin, S. Dolinsek, Bulk and surface characterization of metal powders for direct laser sintering, Vacuum 80 (2005) 29-34.

[32] B. Vrancken, L. Thijs, J.-P. Kruth, J. Van Humbeeck, Microstructure and mechanical properties of a novel $\beta$ titanium metallic composite by Selective Laser Melting, Acta Mater. 68 (2014) 150-158.

[33] M.F. López, A. Gutiérrez, J.A. Jiménez, Surface characterization of new non-toxic titanium alloys for use as biomaterials, Surf. Sci. 482-485 (2001) 300-305.

[34] H. Krauss, C. Eschey, M.F. Zaeh, Thermography for monitoring the selective laser melting process, Sol. Freeform Fabric. 6 (2012) 999-1014.

[35] L.C. Zhang, D. Klemm, J. Eckert, Y.L. Hao, T.B. Sercombe, Manufacture by selective laser melting and mechanical behavior of a biomedical Ti-24Nb-4Zr-8Sn alloy, Scr. Mater. 65 (2011) 21-24.

[36] H. Meier, C. Haberland, J. Frenzel, R. Zarnetta, Selective laser melting of NiTi shape memory components, in: P.J. Bártolo (Ed.), Konferenzbeitrag VR@P, CRC Press/ Balkema, Leiria, 2009.

[37] T. Habijan, C. Haberland, H. Meier, J. Frenzel, J. Wittsiepe, C. Wuwer, C. Greulich, T.A. Schildhauer, M. Köller, The biocompatibility of dense and porous nickel-titanium produced by selective laser melting, Mater. Sci. Eng. 33 (2013) 419-426.

[38] J.H. Dai, Y. Song, Influence of H, C, N and O impurities on the stability of Mg and Al from first-principles calculations, Model. Simul. Sci. Eng. 21 (2013) 1-8.

[39] M.F. Lopez, A. Gutiérrez, J.A. Jiménez, M. Martinesi, M. Stio, C. Treves, Thermal oxidation of vanadium-free Ti alloys: an X-ray photoelectron spectroscopy study, Mater. Sci. Eng. 30 (2010) 465-471.

[40] M. Li, W. Hebenstreit, U. Diebold, A.M. Tyryshkin, M.K. Bowman, G.G. Dunham, A.M. Handerson, The influence of the bulk reduction state on the surface structure and morphology of rutile $\mathrm{TiO}_{2}$ (110) single crystals, J. Phys. Chem. B 104 (2000) 4944-4950.

[41] H. Rath, S. Anand, M. Mohapatra, P. Dash, T. Som, U.P.N. Singh, C. Mishra, D. Kanjilal, D.K. Avasthi, Phase transformation of $\mathrm{TiO}_{2}$ from anatase to rutile by thermal annealing and swift heavy ion irradiation, AIP Conference Proceedings 2008, pp. 250-255.

[42] Y.-Q. Hou, D.-M. Zhuang, G. Zhang, M. Zhao, M.-S. Wu, Influence of annealing temperature on the properties of titanium oxide thin film, Appl. Surf. Sci. 218 (2003) 98-106. 